\title{
Characterization of Self-Assembled Monolayers of Fullerene Derivatives on Gold Surfaces: Implications for Device Evaluations-Supporting Information
}

Yasuhiro Shirai, Long Cheng, Bo Chen and James M. Tour*

Department of Chemistry, Smalley Institute for Nanoscale Science and Technology, Rice University, MS-222, 6100 Main St., Houston, Texas 77005.

tour@rice.edu

Additional SI data

1. Determination of electrode surface area and coverage

2. Solution state CV for selected compounds

3. XPS spectra for compound 19

\section{Determination of electrode surface area and coverage}

The surface area was determined by the $\mathrm{CV}$ for the $\mathrm{Fe}(\mathrm{CN})_{6}{ }^{3-}$ redox at different scan rate and using following relationship;

Peak current, ip $=\left(2.69 \times 10^{5}\right) \mathrm{n}^{3 / 2} \mathrm{~A} \mathrm{D}^{1 / 2} \mathrm{C} \mathrm{v}^{1 / 2}$

where $\quad \mathrm{n}$ : number of electrons...1

A: electrode surface area $\left[\mathrm{cm}^{2}\right]$

D: diffusion coefficient...for $\mathrm{Fe}(\mathrm{CN})_{6}{ }^{3-}$ at $25^{\circ} \mathrm{C} \ldots 0.76 \times 10^{-5}\left[\mathrm{~cm}^{2} / \mathrm{s}\right]$

$\mathrm{C}$ : concentration of $\mathrm{Fe}(\mathrm{CN})_{6}{ }^{3-} \ldots 1[\mathrm{mM}]=1 \times 10^{-6}\left[\mathrm{~mol} / \mathrm{cm}^{3}\right]$

$\mathrm{v}$ : scan rate $[\mathrm{V} / \mathrm{s}]$.

From CV results;
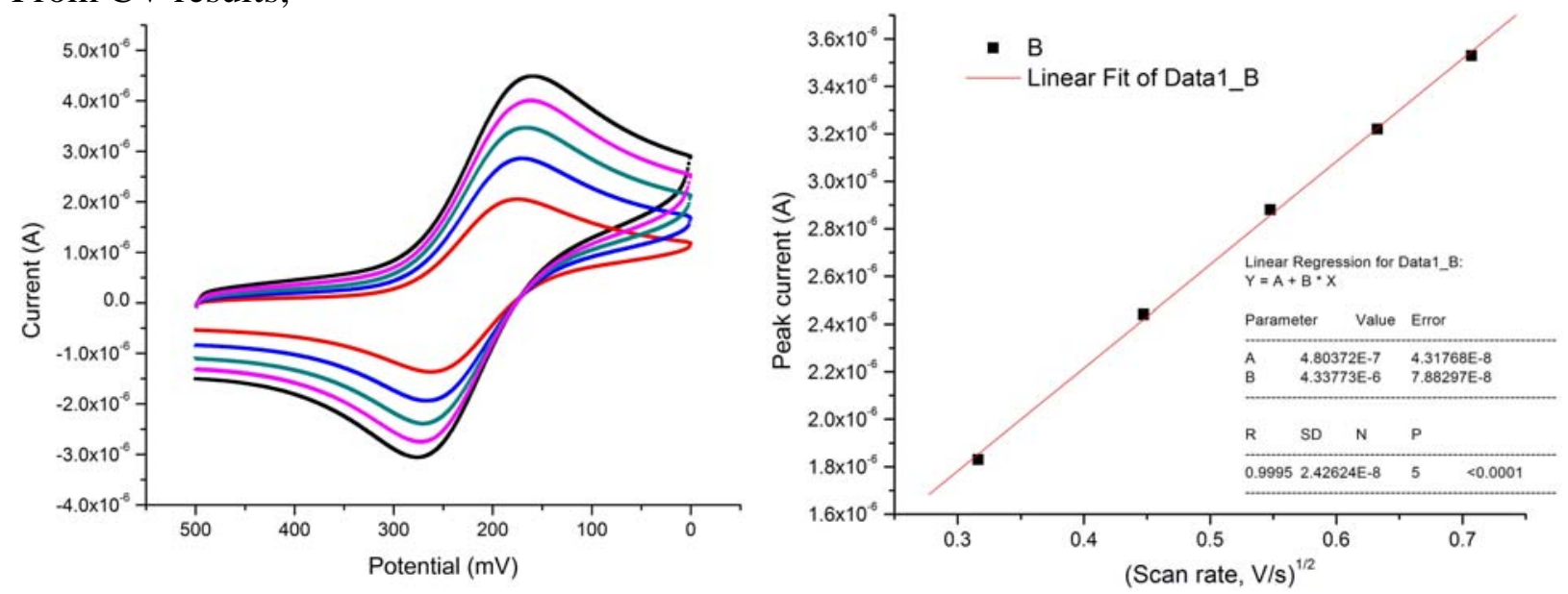
The result agrees with the relationship of the peak current and scan rate, $\left(2.69 \times 10^{5}\right) \mathrm{n}^{3 / 2} \mathrm{~A} \mathrm{D}^{1 / 2} \mathrm{C}=4.3377 \times 10^{-6}$

From this result, electrode surface area was determined to be $A=5.85 \times 10^{-3}\left[\mathrm{~cm}^{2}\right]$.

---- Determination of surface coverage, molecule/nm ${ }^{-2}$-------

The surface coverage can be determined by the surface CV at different scan rate and using following relationship;

Peak current, ip $=\left(9.39 \times 10^{5}\right) \mathrm{n}^{2} \mathrm{~A} \Gamma \mathrm{v}$

where $n$ : number of electrons...1

A: electrode surface area...determined to be $5.85 \times 10^{-3}\left[\mathrm{~cm}^{2}\right]$

$\Gamma$ : surface coverage... [mol $\left./ \mathrm{cm}^{2}\right]$

$\mathrm{v}$ : scan rate $[\mathrm{V} / \mathrm{s}]$

From CV results;
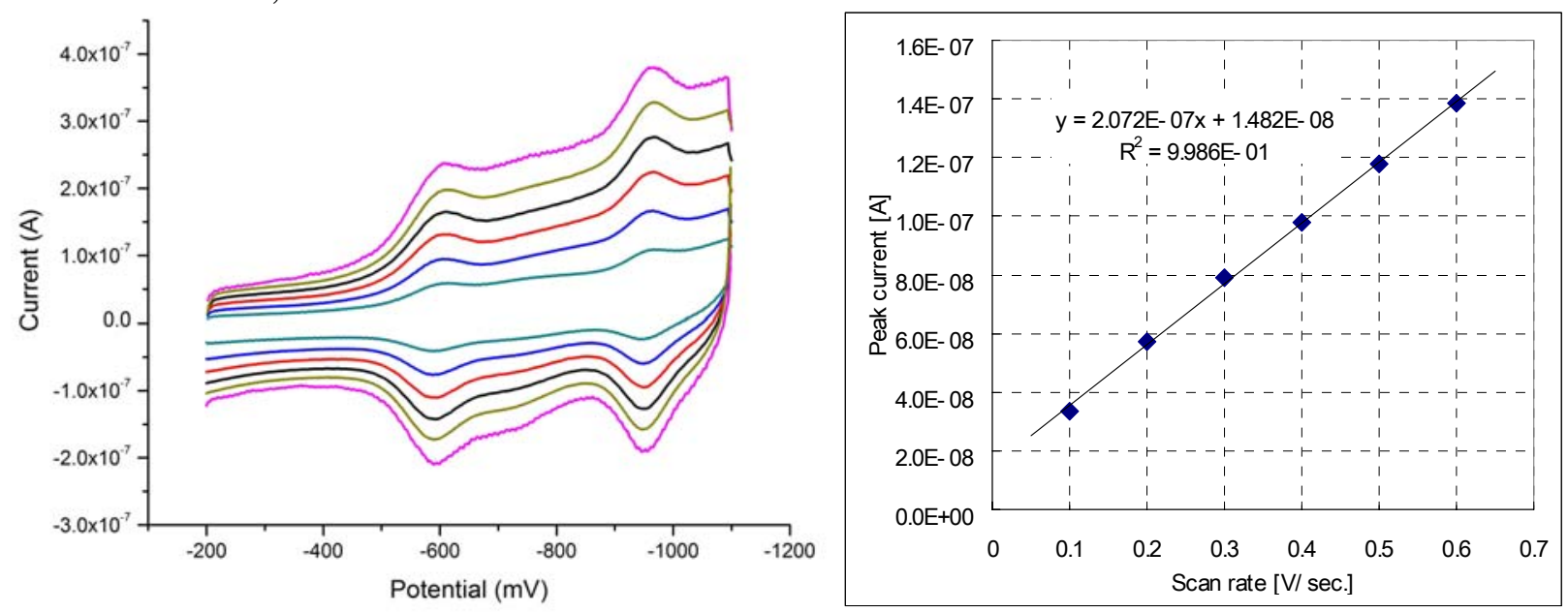

The result agrees with the relationship of the peak current and scan rate, $\left(9.39 \times 10^{5}\right) \mathrm{n}^{2} \mathrm{~A} \Gamma=2.072 \times 10^{-7}$

From this result, $\Gamma=3.77 \times 10^{-11}\left[\mathrm{~mol} / \mathrm{cm}^{2}\right]=0.227$ [molecules $\left./ \mathrm{nm}^{2}\right] \rightarrow 4.41\left[\mathrm{~nm}^{2} / \mathrm{molecule}\right]$ 
2. Solution state CV for selected compounds.

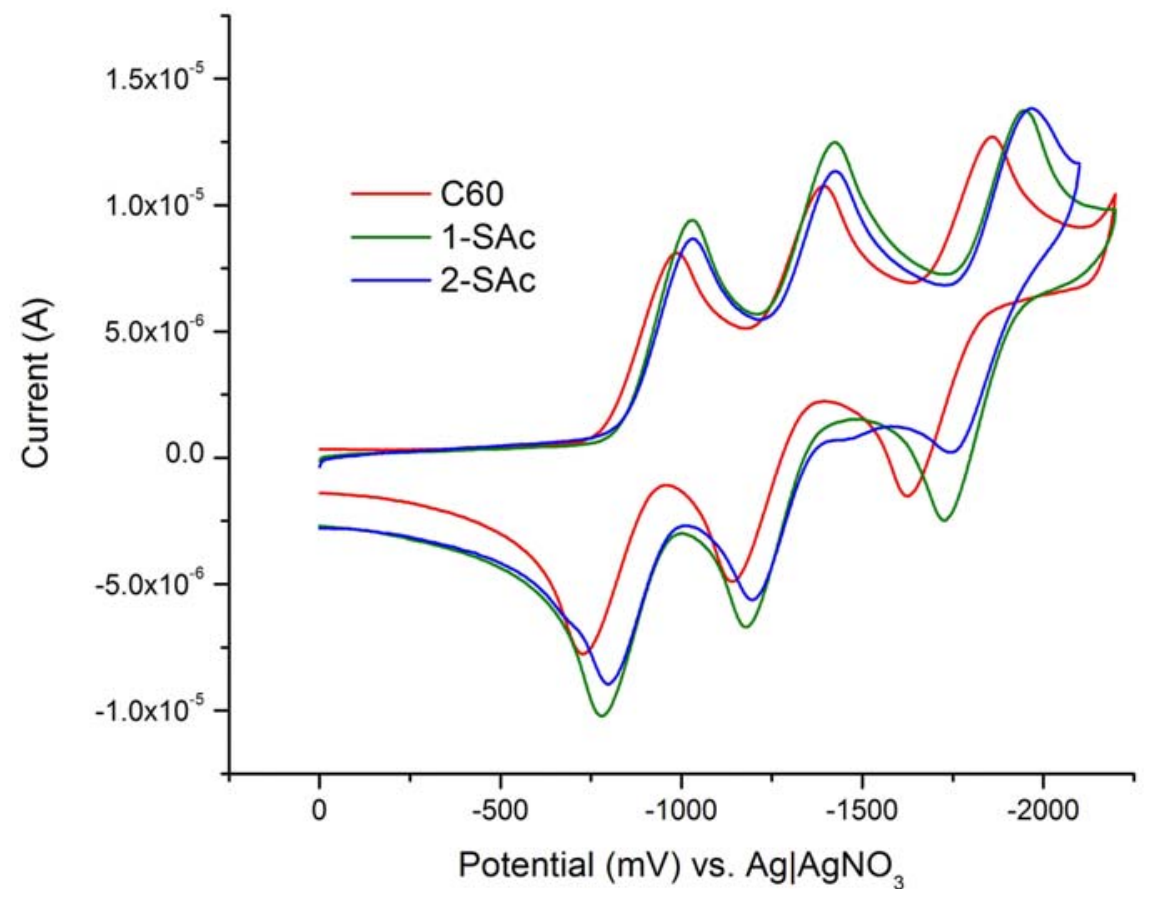




\section{XPS spectra for compound $\underline{19}$.}

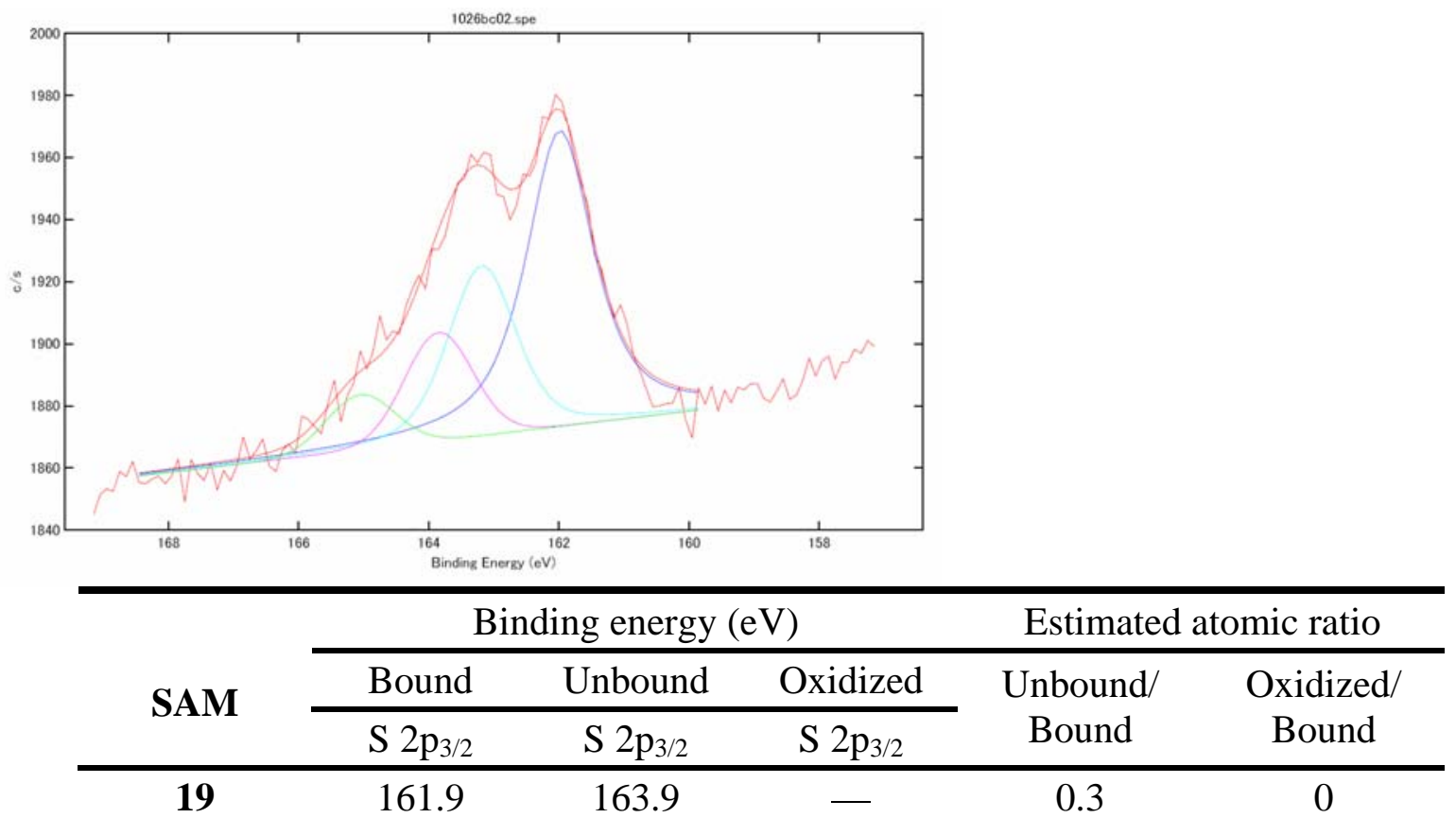

